Original Research Article

\title{
To compare the efficacy and preserved/preservative free nepafenac eye drops in the post cataract inflammation patients
}

\author{
Preet Sood $^{1} *$, Manmohan Bhanot ${ }^{2}$, Narinder Singh ${ }^{1}$
}

\begin{abstract}
${ }^{1}$ Department of Pharmacology, Sri Guru Ram Das Medical College, Amritsar, Punjab, India ${ }^{2}$ Department of Opthalmology, Sri Guru Ram Das Medical College, Amritsar, Punjab, India
\end{abstract}

Received: 03 November 2016

Revised: 06 November 2016

Accepted: 11 November 2016

\section{*Correspondence to:}

Dr. Preet Sood,

Email: preetsood2222@

gmail.com

Copyright: () the author(s), publisher and licensee Medip Academy. This is an openaccess article distributed under the terms of the Creative Commons Attribution NonCommercial License, which permits unrestricted noncommercial use, distribution, and reproduction in any medium, provided the original work is properly cited

\begin{abstract}
Background: Nepafenac is a novel topical NSAID used to treat post operative ocular inflammation and pain. Benzylkonium chloride is used as preservative in the formulation, is notorious in causing ocular surface defect. Now a day, preservative free formulation is available. This study is the comparison of the efficacy and safety of preservative free nepafenac with standard nepafenac eye drop formulation.

Methods: This is a prospective investigator masked randomised parallel trial. Total $n=104$ patients were enrolled. After randomization, patients were divided into two groups (nepafenac withlwithout preservative drug).Patients were examined preoperatively (day-1) and post operatively on days 1, 3, 5, 7, 15 and 30 days. The signs of inflammation and tear film break up time were recorded.

Results: preservative free nepafenac was found better at certain points like aqueous cells at day15 $(\mathrm{p}=0.02)$, conjunctival hyperemia at day $5(\mathrm{p}=0.009)$ and pain at day $3(\mathrm{p}=0.004)$ at other points. Effect on tear film breakup time was recorded but it is not statistically significant.

Conclusions: preservative free nepafenac is found effective in controlling the ocular post inflammation. For evaluating the effect on dryness of eye we need longer trials. Preservative free nepafenac should be preferred over the nepafenac eye drops.
\end{abstract}

Keywords: Benzalkonium chloride, Cataract, Nepafenac, Post operative inflammation, Tear film breakup time

\section{INTRODUCTION}

Nepafenac is a novel NSAID used to treat ocular inflammatory pain after the surgery. ${ }^{1}$ It is found to be much more efficacious in treating post-operative inflammation. Topical NSAIDs although treat the post cataract inflammation they are also found to be notorious in causing ocular surface defect due to their acidic formulation which can present like transient burning and dryness, although it is mild. Addition of preservatives like benzalkonium chloride (BAC) further worsens the problem. $^{2}$ This study was to compare the efficacy and safety of the active ingredients alone /with the preservative containing nepafenac.

The preservative free nepafenac (Nepatop, Entod) eye drops are available in India and it offers a new option to the preserved nepafenac (Nevanac, Alcon) that are currently the most widely used NSAID eye drops after cataract surgery. Comparative data of efficacy and safety of this new preparation of nepafenac vs the BAC preserved preparation of nepafenac are missing. 
We therefore conducted this study to compare the efficacy of preserved nepafenac (Nevanac) versus preservative free Nepafenac (Nepatop) eye drops in the post cataract inflammation patients.

\section{METHODS}

This prospective investigator masked, randomized, parallel group 4 week trial study was conducted from June 2016 to August 2016 in Sri Guru Ram Dass Institute of Medical Sciences, Amritsar. One hundred and four consecutive patients scheduled for small incision cataract surgery with implantation of a posterior chamber intraocular lens were enrolled in the study.

The institutional ethics committee approval was taken.

Patients were included if they were older than 40 years and having non complicated cataract as cortical/ nuclear/ posterior sub capsular cataract.

\section{Exclusion criteria}

Exclusion criteria consisted of history of intraocular inflammation or uveitis, trauma and myopia, significant posterior chamber disease involving macular region, previous macular surgery, previous history of raised intraocular pressure, prolonged steroid therapy, ocular surface epithelial defect, h/o any type of steroid intake, any type of immunocompromised patients, in addition subjects with known hypersensitivity to nepafenac, any ingredients of the study medication were excluded.

\section{Surgical technique}

Preoperatively (day-1) patients were examined with slit lamp to rule out any ocular surface defect. All operations were performed in a standard way and by the same experienced surgeon. Briefly, mydriasis was achieved by instillation of Tropac- $p$ (tropicamide $0.8 \%$ with phenylepherine $5 \%$ ) eye drops. Surgery was performed under peribulbar anesthesia with lignocaine $2 \%$ with adrenaline 1:20000. Small incision cataract surgery was carried out via a temporal sclera tunnel based incision, and a foldable posterior chamber intraocular lens was implanted into the capsular bag. The same irrigating solution (solution Zyonate; Zydus) ophthalmic viscoelastic device were used in all cases. At the end of surgery, difluprednate emulsion along with Nepafenac eye drops (depending upon the study group) was applied in the post operative dressing.

\section{Study medications and study protocol}

Eyes of qualified patients were assigned in a 1:1 ratio to 1 of 2 treatment groups using a computer-generated randomization list. The study medications were preservative-free Nepafenac sodium $0.1 \%$ eye drops, preserved Nepafenac sodium $0.1 \%$ eye drops (preservative, BAC). One drop of the study medication was instilled 4 times daily in the operated eye, starting on the first postoperative day after surgery. Except for the coordinator distributing the study medications, all investigators remain blinded for randomization key throughout the entire study. Anti-inflammatory efficacy was evaluated using the parameters listed below. If not stated otherwise, measurements were performed preceding the surgery (preoperative) and (day 1, 3, 5, 7, $15,30)$.

First day (day 1) postoperatively, the dressing was removed and patient examined under slit lamp for inflammatory signs i.e. aqueous flare, number of aqueous cells and conjunctival hyperemia. The readings were recorded on every subsequent visits (day 1, 3, 5, 7, $15,30)$. The study medication was prescribed according to the randomization key. Moxifloxacin eye drops qid will also be given along with to all the patients for first 7 days. Measurements of ocular tolerability.

\section{Subjective tolerability/pain}

At each postoperative visit, the patient had to mark a position on a visual analog scale measuring $100 \mathrm{~mm}{ }^{3} \mathrm{~A}$ mark close to the 0 position should indicate a very comfortable feeling when applying the drops; a mark close to $100 \mathrm{~mm}$ should indicate severe pain and stinging. Each assessment was independent from the previous one, because the patients did not have access to their earlier assessment(s).

\section{Measurements of anti-inflammatory efficacy}

All the three signs of inflammation i.e. anterior chamber cells, flare, conjunctival hyperemia were examined with slit lamp. The slit lamp light intensity and magnification was kept at maximal. The number of cells/flare is counted in an oblique slit lamp beam $3 \mathrm{~mm}$ long $\times 1 \mathrm{~mm}$ wide and then graded accordingly. While For the pain assessment numeric type of visual analog scale was used. To compare the safety i.e. dry eye we used the tear film breakup time (in mints).

\section{Scale for assessment}

1. Pain was recorded by visual analogue scale (VAS) in which investigator asked the patient to record it on the performa provided. ${ }^{3}$ Every time a new performa is given then it is entered in the patient performa by the investigator. Scale used is absent 0 , mild 1 , moderate 2 , severe 3 and extreme 4 .

2. For aqueous cells: It was counted by slit beam and according to the number of cells present data was entered at each visit in the patient performa by the principal investigator.

3. Aqueous flare was recorded as: Faint-just detectable +1 , Moderate-iris detail clear +2 , Marked- iris detail hazy +3 and for severe fibrinous exudates +4 .

4. Conjunctival hyperemia (bulbar hyperemia): very slight +1 , slight +2 , moderate +3 , severe +4 . 


\section{Safety parameters}

\section{Visual acuity}

Snellen charts were used to measure best-corrected distance visual acuity (VA) and Jaeger reading charts for near Visual Analogue. No VA measurements were recorded on day 1 after surgery.

\section{Tear break up time test (BUT test)}

In this, Fluorescein dye is instilled in lower fornix. Patient is asked to blink several times and then stop. A filter paper is inserted to examine; appearance of dry area is the end point.

The BUT is the interval in last blink and the appearance of first randomly distributed dry spots. Reading less than 10 seconds is abnormal.

In addition, a slit-lamp examination and dilated indirect fundoscopy were performed at every visit.

\section{Patient counselling}

The Patients were educated for any disproportionate swelling or pain in eye if experience, to report back immediately. Mobile telephone number of the PI (principal investigator) was also provided.

\section{Rescue medicine}

Prednisolone acetate $1 \%$ eye drop was kept as rescue drug. In case of excessive inflammation, it had to be used.

\section{Statistical analysis}

Quantitative variables are described using mean \pm standard deviation (SD) or median as well as minimum and maximum value where appropriate. For nominal and ordinal variables, absolute frequencies and percentages are given. To check the normality of the data Kolmogorov- smirnov with life for significance correction or Shapiro-Wilk were applied.

To test whether the 2 medications had comparable baseline values concerning the target variables, either the Pearson chi-square test, fisher's exact test or likelihood ratio were applied, depending on sample distribution.

The Mann-whitney test was used to check quantitative variables for changes over time and influence of medication.

Wilcoxon signed ranks test were applied compare the effect on tear film break up time pre/post operatively. All tests were 2-tailed, and the level of significance was set at $\alpha=0.05$.
Instant statistical pack was used for calculation purposes. With a sample size of 25 eyes per group, a power of 0.8 , $\alpha=0.05$, and an estimated standard deviation of $7 \mathrm{ph} / \mathrm{ms}$, a significant difference in anterior chamber flare between the 2 groups would have been found at a level of 5.2 $\mathrm{ph} / \mathrm{ms}$.

\section{RESULTS}

The data was collected and the findings were as follows.

Table 1: Various parameters.

\begin{tabular}{|llll|}
\hline Parameters & $\begin{array}{l}\text { Mean } \pm \text { SD } \\
\text { (Preservative } \\
\text { free nepafenac) }\end{array}$ & $\begin{array}{l}\text { Mean } \pm \text { SD } \\
\text { (Nepafenac) }\end{array}$ & $\begin{array}{l}\text { P } \\
\text { value }\end{array}$ \\
\hline Aqueous cells 5 & $1.40+0.10$ & $1.08+0.055$ & 0.009 \\
\hline $\begin{array}{l}\text { Aqueous cells } \\
\text { 15 }\end{array}$ & $0.52+0.102$ & $0.56+0.10$ & 0.02 \\
\hline $\begin{array}{l}\text { Conjuctival } \\
\text { hyperemia 5 }\end{array}$ & $0.60=0.1$ & $0.92+0.55$ & 0.009 \\
\hline Pain 3 & $0.20+0.082$ & $0.60+0.1$ & 0.004 \\
\hline $\begin{array}{l}\text { Tear film } \\
\text { breakup time 3 }\end{array}$ & $12.68+0.11$ & $13.40+0.173$ & 0.002 \\
\hline $\begin{array}{l}\text { Tear film } \\
\text { breakup time 5 }\end{array}$ & $12.40+0.13$ & $13.08+0.172$ & 0.007 \\
\hline $\begin{array}{l}\text { Tear film } \\
\text { breakup time 7 }\end{array}$ & $11.72+0.19$ & $12.92+0.152$ & 0.000 \\
\hline $\begin{array}{l}\text { Tear film } \\
\text { breakup time 15 }\end{array}$ & $11.24+0.21$ & $11.88+0.233$ & 0.05 \\
\hline $\begin{array}{l}\text { Tear film } \\
\text { breakup time 30 }\end{array}$ & $10.24+0.26$ & $11.48+0.24$ & 0.002 \\
\hline
\end{tabular}

Preservative free nepafenac was found significantly better at aqueous cells at day1 $5 \quad(\mathrm{p}=0.02)$, conjuctival hyperemia at day $5(\mathrm{p}=0.009)$.

Statistically significant $(\mathrm{p}=0.004)$ effect on pain at day 3 was also observed with Preservative free nepafenac as compared to nepafenac.

Preservative free formulation has substantially decreased the tear film breakup time at all the points and the results are highly significant. ${ }^{6}$

Nepafenac has shown significant effect only at one point i.e. aq. Cells at day $5(\mathrm{p}=0.009)$.

At all other points, with and without preservative nepafenac are found to be equally effective.

\section{DISCUSSION}

Nepafenac $0.1 \%$ is the newest topical NSAID available for the treatment of ocular pain and inflammation associated with cataract surgery. It has unique properties, including rapid corneal permeability and targeted intraocular activation due to its pro drug structure. ${ }^{1}$ 
In the present study, the efficacy in controlling postoperative intraocular inflammation, measured as anterior chamber flare, conjuctival hyperemia and aqueous cells was comparable for all 2 treatment groups.

Statistically significant differences were found concerning the tolerability parameters evaluated: preservative-free nepafenac sodium eye drops were shown to be better tolerated both in subjective rating on a visual analog scale, as well as in ocular discomfort assessment determined during slit-lamp examination when compared with preserved nepafenac. Depending on the method used, differences were less or more obvious.

Visual analog scales have been proven to be useful tools in measuring ocular discomfort and pain. ${ }^{3}$ A rating performed by the patient is more sensitive than an observer-based assessment of clinical signs, and therefore, in our opinion, it is even more relevant in evaluating a patient's discomfort. In our study, a steady increase of discomfort when applying the drops was found for both preparations containing a preservative, but was only minimal for the preservative-free eye drops. An additional approach was the observer-based questioning about general ocular discomfort.

Similar to the trends observed with ocular discomfort, conjunctival hyperemia also showed a dependency on which medication was applied. Again, patients receiving preservative-free nepafenac eye drops exhibited a greater reduction of conjunctival hyperemia between day 1 and 1 week after surgery than patients receiving preserved eye drops.

These findings indicate that conjunctival hyperemia in the early postoperative phase (day 1) can be seen mainly as an irritation after surgery that then recovers over the following weeks, but may be prolonged by preservatives contained in the eye drops. Alternatively, the preservatives potentially themselves cause conjunctival injection as a consequence of irritation.

Although numerous studies are in concordance to our finding that both nepafenac sodium as with /without preservative are effective for treating postoperative intraocular inflammation.

After intensive search on PubMed, Medline, Cochrane library, only two studies have looked at both effectiveness as well as tolerability of preserved versus preservative-free NSAID eye drops but the drug used is Diclofenac. $^{4,5}$

In other study by Maca et al, all 3 formulations demonstrated equal anti-inflammatory efficacy as measured by reduction of anterior chamber flare after surgery and prevention of postoperative macular edema. ${ }^{5}$ Patients treated with preservative-free diclofenac eye drops reported significantly better subjective tolerability, and experienced earlier reduction of postoperative conjunctival hyperemia.

The preserved eye drops used in our study contained BAC, a quaternary cationic surfactant. Toxic effects include modifying the structure and physiologic features of the epithelium, reducing tear production, and shortening tear break-up time. ${ }^{6}$ Baudouin and associates showed reduced tear film stability with BAC-preserved eye drops already 3 hours after instillation of the first drop in healthy eyes. ${ }^{7}$

This immediate effect on ocular surface may explain why, in our study, tear film breakup time decreased at all the points and results are found to be statistically significant in patients applying preserved eye drops, whereas preserved eye drops over an equal 4-week observation period with their property to cause delayed hypersensitivity reactions still were tolerated well.

Preservative free formulation is found to be significantly better in controlling aqueous cells and conjunctival hyperemia this may be due to less interface in the natural healing process usually aninherent property of preservative itself. Conjunctival hyperemia also more or less accounts for ocular discomfort.

\section{CONCLUSION}

In conclusion, topical, preservative-free nepafenac sodium $0.1 \%$ eye drops provide effective prevention and control of postoperative inflammation over a 1-month observation period with significantly improved patient tolerability when compared with eye drops containing an NSAID plus BAC as a preservative. In view of these results and bearing in mind the significant cytotoxicity of preservatives, ophthalmologists should consider treatment with new-generation preparations containing no or low-risk preservation.

Funding: No funding sources

Conflict of interest: None declared

Ethical approval: The study was approved by the Institutional Ethics Committee

\section{REFERENCES}

1. Nardi M, Lobo C, Bereczki A, Cano J, Zagato E, Potts $\mathrm{S}$, et al. Analgesic and anti-inflammatory effectiveness of nepafenac $0.1 \%$ for cataract surgery. Clin Ophthalmol. 2012;6:997-1004.

2. Huang C, Chen W, Chen Y, Liu Z. Toxicity research status of benzalkonium chloride on ocular surface. $\mathrm{Br} \mathrm{J}$ Ophthalmol. 2011;95(6):869-75.

3. Woods CA, Cumming B. The impact of test medium on use of visual analogue scales. Eye Contact Lens 2009;35:6-10.

4. Weber BME, Arnoux YV, Jaulerry SD, LeHoang P, Colin J. Comparison of the efficacy and safety of two formulations of diclofenac sodium $0.1 \%$ eye drops in 
controlling postoperative inflammation after cataract surgery. Eur J Ophthalmol. 2005;15(6):702-11.

5. Maca, Chiambaretta F, Creuzot-Garcher C, Pilon F. Ocular tolerance of a new formulation of non-preserved diclofenac. J Fr Ophtalmol. 2004;27:739-44.

6. Huber-van der Velden KK, Thieme H, Eichhorn M. Morphological alterations induced by preservatives in eye drops. Ophthalmologe. 2012;109(11):1077-81.
Cite this article as: Sood P, Bhanot M, Singh N. To compare the efficacy and preserved/ preservative free nepafenac eye drops in the post cataract inflammation patients. Int J Basic Clin Pharmacol 2016;5:2384-8. 